\title{
Comments on: Shared resources in collaborative vehicle routing
}

\section{Martin Bichler ${ }^{1}$}

Published online: 16 March 2020

(C) The Author(s) 2020

\section{Comments}

This paper presents an up-to-date review of the emerging literature on collaborative vehicle routing. More generally, it summarizes the literature in operations research (OR) and logistics that focuses on problems with multiple decision-makers. OR has a long and successful history in solving computationally hard resource allocation problems. The traveling salesman problem is a classical problem in this field and its solution has seen enormous advances in the last 60 years. Although the problem is computationally hard (NP-hard), instances with millions of cities can be solved nowadays within 2-3\% of an optimal tour (Rego et al. 2011). This is far beyond what experts could imagine 20 years ago.

To a large extent, problems in OR have been solved from the point of view of a single decision-maker. However, many of the problems and inefficiencies that we experience in logistics and transportation nowadays arise from the fact that multiple parties need to coordinate and allocate scarce resources efficiently. Such resources might be loading docks at warehouses (Karaenke et al. 2018), airport time slots (Ball et al. 2007), or road capacity (Cramton et al. 2018). There is a significant empirical literature showing that these resources are not used efficiently, which is due to a lack of coordination among the participants or inefficient allocation mechanisms. Gansterer and Hartl mention that empty truck miles in the EU are estimated to range between 15 and $20 \%$, and that in the US, trailers of trucks are on average only $43 \%$ full and $25 \%$ of the total miles traveled are with completely or nearly empty trailers. The lack of coordination among carriers can be seen as a root cause for these inefficiencies.

Economic theory suggests that markets allocate resources efficiently. The Arrow-Debreu model shows that under convex preferences, perfect competition, perfectly divisible goods, and demand independence there must be a set of

This comment refers to the invited paper available at https://doi.org/10.1007/s11750-020-00541-6.

Martin Bichler

bichler@in.tum.de

1 Technical University of Munich, Munich, Germany 
competitive equilibrium prices that implement the efficient outcome (Arrow and Debreu 1954). Market participants are price-takers, and they sell or buy goods to maximize their total utility subject to their budget or initial wealth in this model. The results derived from the Arrow-Debreu model led to the well-known welfare theorems, an important argument for markets as an efficient way to allocate resources. The first theorem states any competitive equilibrium leads to a Pareto efficient allocation of resources. The second theorem states that any efficient allocation can be attained by a competitive equilibrium under the Arrow-Debreu model assumptions.

However, general equilibrium theory has strong assumptions, and the results of these models do not necessarily carry over to the complex environments that we face today in logistics, transportation and supply chain management. For example, goods are indivisible (e.g., time slots at airports or warehouses), participants have complex preferences including substitutes and complements (e.g., a package of a departure and an arrival time slot), and supply and demand need to be matched dynamically over time (e.g., trips matched to available road capacity over time). It is far from obvious how markets need to be designed such that they maximize welfare and are in a competitive equilibrium. Collaborative vehicle routing is an important problem in this context and the focus of the survey by Gansterer and Hartl.

The authors motivate the topic with the inefficiencies that have been reported empirically and that are due to a lack of coordination among carriers. The literature is classified in centrally planned collaborations where the center has full information and decentral collaborations, where partners agree only on mechanisms, but do not have full information. In addition, they refer to horizontal collaborations for companies on the same level of the supply chain and vertical collaboration for cooperation between manufacturers and carriers, for example.

Gansterer and Hartl focus on road transportation and papers with a focus on operations research in their work. After an introduction and motivation in Section 1, Section 2 provides an overview of how literature was selected and definitions. Section 3 focuses on centrally planned collaborations. The authors survey 29 papers in this category. Most of this literature focuses on LTL and only a few papers analyze FTL shipments. The solutions presented are largely based on the traditional literature on vehicle routing, but several studies discuss fair cost allocation (or profit sharing) via the Shapley value or related concepts. Various problems arise even with central planning and complete information. For example, workloads might be distributed among the carriers unevenly and the planner needs to consider long-term business relationship in the assignment. Some authors also analyze coalition formation and the existence of core-stable solutions to such cooperative games. Gansterer and Hartl derive four research directions from this survey: (1) integration of horizontal and vertical collaborations, (2) collaborations in multi-layer networks, (3) coverage of different problem classes, and (4) appropriate and fair profit sharing mechanisms. Regarding the latter, the authors highlight the computational effort for computing the Shapley value, but also the fact that only costs (or profit) are considered. In collaborative vehicle routing, multiple-objective matter such as the number of reallocated customers or fairness across multiple periods rather than just one. Overall, the assumption of a fully informed decision maker in centralized collaboration is a strong one. 
The literature on decentralized collaborations takes the incomplete information of participants into consideration. Gansterer and Hartl introduce economic design desiderata such as efficiency, incentive compatibility, individual rationality, and budget balance. Much less has been published on decentralized collaborative vehicle routing. The authors highlight some articles on combinatorial auctions and exchanges which allow for bidding on routes. Such mechanisms are particularly suitable to logistics where costs for lanes on a route are sub-additive. The survey provides five directions for future research including (1) the usage of real-world data, (2) the application of data analytics methods, (3) information sharing, (4) alternative allocation mechanisms, and (5) strategic behavior in auction-based collaborations. Gansterer and Hartl provide ideas how machine learning can be used to recover not only preferences of participants and emphasize the strategic difficulties in such auctions, but also the fact that manipulation is challenging because of the informational requirements participants would need to have.

The survey concludes with a brief summary, which highlights that there has been increasing interest in collaborative vehicle routing, but that the research on distributed collaboration is still in its infancy. It is a field that requires new methods and OR needs to be cognizant of work that has been published on market design in the recent years. Market design is an interdisciplinary field that has drawn significant attention in computer science, OR, and economics (Roth 2018; Bichler 2017). For example, the INFORMS has a relatively new section on Auctions and Market Design that combines research at the intersection of these three communities. Also, several journals have established new departments to publish work in this field. The survey by Gansterer and Hartl provides an up-do-date account of the market design literature with a focus on collaborative vehicle routing and is a very good starting point for everyone interested in this emerging field.

Acknowledgements Open Access funding provided by Projekt DEAL.

Open Access This article is licensed under a Creative Commons Attribution 4.0 International License, which permits use, sharing, adaptation, distribution and reproduction in any medium or format, as long as you give appropriate credit to the original author(s) and the source, provide a link to the Creative Commons licence, and indicate if changes were made. The images or other third party material in this article are included in the article's Creative Commons licence, unless indicated otherwise in a credit line to the material. If material is not included in the article's Creative Commons licence and your intended use is not permitted by statutory regulation or exceeds the permitted use, you will need to obtain permission directly from the copyright holder. To view a copy of this licence, visit http://creativecommons.org/licen ses/by/4.0/.

\section{References}

Arrow KJ, Debreu G (1954) Existence of an equilibrium for a competitive economy. Econometrica 22(3):265-290

Ball MO, Ausubel LM, Berardino F, Cramton P, Donohue G, Hansen M, Hoffman K (2007) Marketbased alternatives for managing congestion at New Yorks laguardia airport. In: AirNeth Annual Conference, The Hague

Bichler M (2017) Market design: a linear programming approach to auctions and matching. Cambridge University Press, Cambridge 
Cramton P, Geddes RR, Ockenfels A (2018) Set road charges in real time to ease traffic. Nature 560:23-25

Karaenke P, Bichler M, Minner S (2018) Coordination is hard: electronic market mechanisms for increased efficiency in transportation logistics. Manage Sci 65:5884-5900

Rego C, Gamboa D, Glover F, Osterman C (2011) Traveling salesman problem heuristics: leading methods, implementations and latest advances. Eur J Oper Res 211(3):427-441

Roth AE (2018) Marketplaces, markets, and market design. Am Econ Rev 108(7):1609-58

Publisher's Note Springer Nature remains neutral with regard to jurisdictional claims in published maps and institutional affiliations. 